\title{
Thermal Analysis and Validation of UV and Visible Spectrophotometric Methods for the Determination of New Antibiotic Tigecycline in Pharmaceutical Product
}

\author{
Lucélia Magalhães da Silva*, Adélia Emilia de Almeida, Hérida Regina Nunes Salgado \\ Department of Drugs and Medicines, School of Pharmaceutical Sciences of Araraquara- UNESP, Rodovia Araraquara-Jaú, km 1, CEP \\ 14801-902, Araraquara, SP, Brazil
}

\begin{abstract}
This work has proposed the development and validation of ultraviolet (UV) and visible spectrophotometric methods for determination of tigecycline in lyophilized powder. In UV method tigecycline showed absorption maximum at $245 \mathrm{~nm}$, in aqueous medium, where as in visible spectrophotometric method it reacts with copper acetate reagent, under acid conditions, forming a greenish coloured solution with absorption maximum at $378 \mathrm{~nm}$. Thermogravimetric Analysis and Differencial Scanning Calorimetry (TGA-DSC) techniques were studied to determine the thermal analysis of tigecycline. The methods were completely validated according to the International Conference on Harmonization (ICH) guidelines, showing good accuracy, precision, selectivity, robustness and linearity. Therefore the methods were found to be simple, economic and free of polluting reagents, being suitable for the analysis of the lyophilized powder formulation, contributing to improve the quality control and to assure its therapeutic efficacy.
\end{abstract}

Keywords Tigecycline, Spectrophotometric Methods, Thermal Analysis

\section{Introduction}

Tigecycline exhibits robust activity against bacterial isolates resistant to other antibiotic classes, including betalactams and fluoroquinolones, while resisting deactivation by most of the known tetracycline resistance mechanisms found in clinically significant bacteria[1]. This antibiotic has been evaluated as monotherapy for serious infections in human clinical trials as a result of its microbiological, pharmacodynamic and pharmacokinetic properties[2,3].

Tigecycline is structurally derived from minocycline by adding a tert-butyl-glycylamido side chain to carbon 9 of the $\mathrm{D}$ ring of the tetracycline backbone[4]. The Figure 1 depicts the structural formulas of tigecycline[5]. Chemically, tigecycline is [( $4 \mathrm{~S}, 4 \mathrm{aS}, 5 \mathrm{aR}, 12 \mathrm{aS})-9$ - $(2$ - tert- Butylaminoacetylamino)-4,7-bis-dimethylamino-3,10,12,12a-tetrahy droxy-1,11-dioxo-1,4,4a,5,5a,6,11,12a-octahydronaph-tha cene-2-carboxamide]. Its chemical formula is $\mathrm{C}_{29} \mathrm{H}_{39} \mathrm{~N}_{5} \mathrm{O}_{8}$, and its molecular weight is 585.65 Daltons[6,7].

There are few methods described to analyze tigecycline and its metabolites in the literature. Four HPLC-UV assays for the determination of tigecycline in biological materials have been described in the literature [6, 8-11]. Besides

* Corresponding author:

lucmsil@yahoo.com.br (Lucélia Magalhães da Silva)

Published online at http://journal.sapub.org/aac

Copyright (C) 2012 Scientific \& Academic Publishing. All Rights Reserved
HPLC-UV, HPLC/MS/MS methods have also been employed to determination of tigecycline in biological fluids and tissues, as serum, urine, bronchoscopy and bronchoalveolar lavage, alveolar cells, gall bladder, bile, colon, bone, synovial fluid, lung and rat bone[6,10,12-14].<smiles>CN(C)c1cc(NC(=O)CNC(C)(C)C)c(O)c2c1C[C@H]1C[C@H]3[C@H](N(C)C)C(O)=C(C(N)=O)C(=O)[C@@]3(O)C(O)=C1C2=O</smiles>

Figure 1. Chemical structure of tigecycline

The literature has reported analytical methods for determination of antibiotics such as chromatography, spectroscopy, spectrophotometry and microbiological assay. The microbiological assay is the most commonly used routine method. However, it is slow, often inaccurate, and subject to interference by other antibiotics[15]. Though modern methods of analysis (HPLC, GLC, NMR and Mass) for purity assay of any drug afford simplicity, speed, good specificity and excellent precision and accuracy, they involve sophisticated equipments, which are not in the reach of most laboratories and small-scale industries. Moreover, they pose problems of maintenance[16]. On the other hand, spectrophotometry has always provided analytical techniques characterized by instrumental simplicity, moderate cost and portability. These features make spectrophotomet- 
ric techniques particularly suitable for the determination of low concentrations of clinically important compounds[17].

The tigecycline is commercially available, but at the moment, there is no spectrophotometric method published for the quantitative analysis of this drug. Therefore, the aim of the present article was to develop and validate two simple and fast spectrophotometric methods for the quantitative analysis of tigecycline in lyophilized powder, contributing to improve the quality control and assuring the therapeutic efficacy. This paper reports procedures for the quantitation of the drug in pharmaceutical forms by visible and ultraviolet lights spectrophotometry, providing precise and accurate results validated by statistical analysis as well as being low cost methods.

\section{Experimental}

\subsection{Chemical and Reagents}

The tigecycline reference substance was purchased from Sequoia Research Products (Oxford, UK). Batches of Tygacil® (Wyeth, USA) lyophilized powder, containing $50 \mathrm{mg}$ of tigecycline were obtained from commercial sources within their shelf-life period. Copper acetate was purchased from Merck (Darmstadt, Germany) and sodium acetate from Synth (Diadema, Brazil). All chemicals used were of pharmaceutical or special analytical-grade. For all of the analyses, ultrapure water was purified using an Elix 3 coupled to a Milli-Q Gradient A10 system (Millipore, Massachusetts, USA).

The placebo solution was prepared in the laboratory by addition of appropriate amount of pharmaceutical grade excipient monohydrate lactose in purified water.

The acetate buffer $\mathrm{pH} 3.0$ was prepared by dissolving $4.0 \mathrm{~g}$ of anhydrous sodium acetate in $800 \mathrm{~mL}$ of water. Sufficient amount of glacial acetic acid (about $130 \mathrm{~mL}$ ) was added to adjust $\mathrm{pH}$. The solution was transferred into a $1000 \mathrm{~mL}$ volumetric flask e diluted to $1000 \mathrm{~mL}$ with water.

To prepare the copper acetate solution, $5.0 \mathrm{~g}$ of copper acetate were weighted and transferred into a $100 \mathrm{~mL}$ volumetric flask, $80 \mathrm{~mL}$ of water was added and the solution was placed in ultrasonic bath for 30 minutes, then the volume was completed with water.

\subsection{Apparatus}

All absorbance measurements were performed on a UV-Vis Recording Spectrophotometer UV-mini 1240 (Shimadzu®, Kyoto, Japan), using $1.0 \mathrm{~cm}$ quartz cells. To adjust of buffer $\mathrm{pH}$, in the visible method, a digital $\mathrm{pHmeter}$ B474 (Micronal ${ }^{\circ}$, São Paulo, Brazil) was used. TGA (thermogravimetric analysis) curves were obtained with a SDT-2960 (TA Instruments) thermal analyzer apparatus

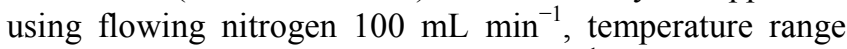
$25-1000^{\circ} \mathrm{C}$, at a heating rate of $10^{\circ} \mathrm{C} \mathrm{min}^{-1}$. The DSC curves were obtained with a DSC-2910 (TA Instruments) equipment using flowing nitrogen $25 \mathrm{~mL} \mathrm{~min}^{-1}$. The tigecycline mass applied was $4.00 \pm 0.4 \mathrm{mg}$ to the two thermal analysis.

\subsection{Preparation of Reference Substance Solution}

\subsubsection{UV Method}

The stock solution was daily prepared by weighing accurately, $5 \mathrm{mg}$ of tigecycline reference substance, transferred to $100 \mathrm{~mL}$ volumetric flask and diluted to volume with water, obtaining a concentration of $50 \mu \mathrm{g} \mathrm{mL}^{-1}$ of tigecycline.

\subsubsection{Visible Method}

The stock solution was daily prepared by weighing accurately, $5 \mathrm{mg}$ of tigecycline reference substance, transferred to $25 \mathrm{~mL}$ volumetric flask and diluted to volume with water, obtaining a concentration of $200 \mu \mathrm{g} \mathrm{mL}^{-1}$ of tigecycline.

\subsection{Preparation of Sample Solutions}

\subsubsection{UV Method}

To prepare the sample solution, vials containing $50 \mathrm{mg}$ of tigecycline were accurately weighed and mixed. An appropriated amount was transferred into an individual $50 \mathrm{~mL}$ volumetric flask and diluted to volume with water. The final concentration of $50 \mu \mathrm{g} \mathrm{mL} \mathrm{m}^{-1}$ of the active pharmaceutical ingredient was daily prepared, diluted to an appropriate concentration with water, analyzed and the amount of the drug calculated against the reference substance.

\subsubsection{Visible Method}

To prepare the sample solution, vials containing $50 \mathrm{mg}$ of tigecycline were accurately weighed and mixed. An appropriated amount was daily transferred into an individual 25 $\mathrm{mL}$ volumetric flask and diluted to volume with water, obtaining final concentration of $200 \mu \mathrm{g} \mathrm{mL}^{-1}$ of the active pharmaceutical ingredient. Aliquots of this solution were transferred to volumetric flask to reaction with copper acetate, in acid $\mathrm{pH}$, and diluted to an appropriate concentration with water, analyzed and the amount of the drug calculated against the reference substance.

\subsection{Spectrophotometric Measurements}

\subsubsection{UV Method}

Aliquots of reference substance and sample solutions were transferred into a $10 \mathrm{~mL}$ volumetric flasks and the volume was brought to the volume with water and the absorbance was measured at $245 \mathrm{~nm}$ against a reagent blank prepared simultaneously.

\subsubsection{Visible Method}

Aliquots of reference substance and sample solutions were transferred into a $10 \mathrm{~mL}$ volumetric flasks, followed by addition of $1 \mathrm{~mL}$ of acetate buffer, then $1 \mathrm{~mL}$ of $5 \%(\mathrm{w} / \mathrm{v})$ copper acetate solution and the volume was brought to the volume with water and the absorbance was measured at 378 $\mathrm{nm}$ against a reagent blank prepared simultaneously. 


\subsection{Validation of the RP-LC Method}

The methods were validated using samples of pharmaceutical formulations with the label claim of $50 \mathrm{mg}$ by determinations of the following parameters: specificity, linearity, precision, accuracy, limit of detection (LOD), limit of quantitation (LOQ) and robustness, following the International Conference on Harmonization (ICH) guidelines[18].

\subsubsection{Specificity}

Selectivity was evaluated by analysis of the placebo solutions and the tigecycline working standard solution at the concentration of 16 and $22 \mu \mathrm{g} \mathrm{mL}^{-1}$, to ultraviolet and visible methods, respectively. The placebo solution containing the excipient monohydrate lactose of the pharmaceutical formulation was prepared for this study. It was treated in the same manner as the commercial samples.

\subsubsection{Linearity and Range}

The linearity was determined by constructing three independent analytical curves, each one with seven reference substance concentrations of tigecyline in triplicate, in the range of 10-22 and 10-34 $\mu \mathrm{g} \mathrm{mL}^{-1}$, to ultraviolet and visible methods, respectively. The absorbance values were plotted against the respective concentrations of tigecycline to obtain the analytical curve. The results were subjected to regression analysis by a least-squares method to calculate calibration equation and determination coefficient.

\subsubsection{Precision and Accuracy}

The precision of the method was determined by the repeatability and the intermediate precision. Repeatability was examined by six evaluations of the same concentration sample of tigecycline, on the same day, and under the same experimental conditions. The intermediate precision of the method was assessed by carrying out the analysis on three different days (inter-days), and also by other analysts performing the analysis in the same laboratory (between- analysts). In the ultraviolet method, the accuracy was evaluated by applying the proposed method to the analysis of known amounts of the reference substance added to sample solution containing $10 \mu \mathrm{g} \mathrm{mL}^{-1}$ of tigecycline, to obtain solutions at concentrations of $12.8 ; 16$ and $19.2 \mu \mathrm{g} \mathrm{mL}^{-1}$, equivalent to 80,100 and $120 \%$ of the nominal analytical concentration, respectively. In the visible method, solutions at concentrations of $17.6 ; 22$ and $26.4 \mu \mathrm{g} \mathrm{mL}^{-1}$ were obtained by addition of known amounts of the reference substance to sample solution containing $14 \mu \mathrm{g} \mathrm{mL}^{-1}$ of tigecycline. The accuracy of the methods was calculated as the percentage of the drug recovered from the sample.

\subsubsection{Limits of Detection and Quantitation}

The limit of detection (LOD) and the limit of quantitation (LOQ) were calculated, as defined by ICH (2005)[18], using the mean values of three independent analytical curves, determined by a linear-regression model, where the factors 3.3 and 10 for the detection and quantitation limits, respec- tively, were multiplied by the ratio from the standard deviation of the intercept and the slope.

\subsubsection{Robustness}

Three sample solutions were prepared and analyzed using the established conditions and by variation of the following analytical parameters: wavelength, volume of copper solution added (0.8-1.2 $\mathrm{mL})$ and buffer $\mathrm{pH}(2.5-3.5)$. Tigecycline contents and R.S.D. were determined for each condition.

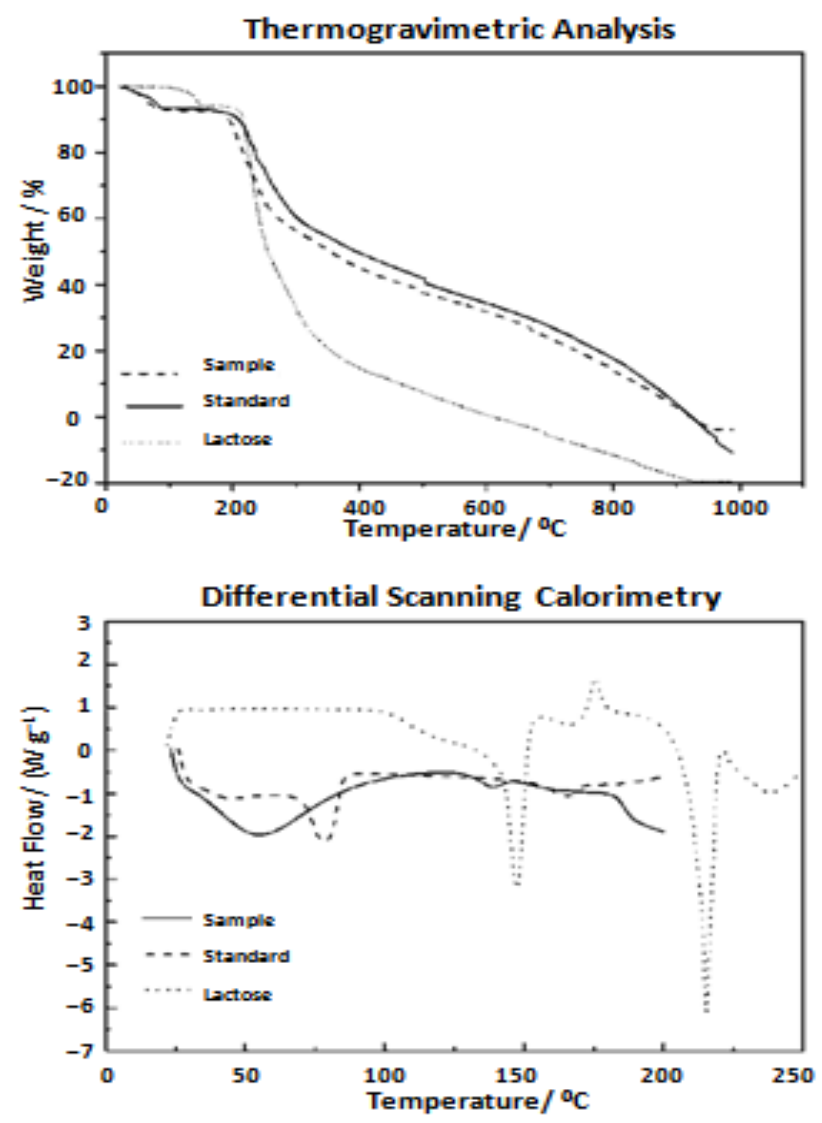

Figure 2. Thermal analysis of tigecycline

\section{Results and Discussion}

\subsection{Thermal Analysis}

The thermal analysis of the tigecycline standard and pharmaceutical product and the excipient monohydrate lactose was studied by Thermogravimetric Analysis- Differential Scanning Calorimetry (TGA-DSC) techniques. The TGA-DSC curves of tigecycline and lactose are shown in Figure 2. The tigecycline was heated from $25^{\circ} \mathrm{C}$ up to $1000^{\circ} \mathrm{C}$. The TGA curves showed that the tigecycline standard was more thermally stable than the pharmaceutical product, since that the standard started its decomposition at $188.6^{\circ} \mathrm{C}$ and the sample at $175.3^{\circ} \mathrm{C}$. The loss of the water happened between 33 and $127^{\circ} \mathrm{C}$ to sample and between 41 and $99^{\circ} \mathrm{C}$ to standard. The decomposition of lactose was observed at $198.4^{\circ} \mathrm{C}$ and the water loss happened between 89 and $161^{\circ} \mathrm{C}$. In the DSC 
curve of tigecycline sample, a water loss was observed followed by decomposition, indicating its amorphous state, and a melting point peak was not observed. To standard, the DSC curve showed water loss and after a melting point endothermic peak at $78.3^{\circ} \mathrm{C}$, followed by its decomposition. The DSC curve of lactose showed water loss and after a melting point endothermic peak at $147.2^{\circ} \mathrm{C}$, followed by crystallization verified in the exothermic peak at $175.6^{\circ} \mathrm{C}$. It was observed a melting point endothermic peak at $215.1^{\circ} \mathrm{C}$ and enthalpy of $71.1 \mathrm{~J} \mathrm{~g}^{-1}$. After, an additional endothermic peak at $236.4^{\circ} \mathrm{C}$ was formed, related to thermal decomposition of the melted compound.

\subsection{Ultraviolet Method}

The proposed UV method allows a rapid and economical quantitation of tigecycline in lyophilized powder without any time-consuming sample preparation. Moreover, the spectrophotometric methods involve simple instrumentation compared with other instrumental techniques. The absorption spectra of tigecycline in aqueous solution is shown in Figure 3 . The $\lambda$ max was found to be $245 \mathrm{~nm}$. This wavelength was used for all measurements.

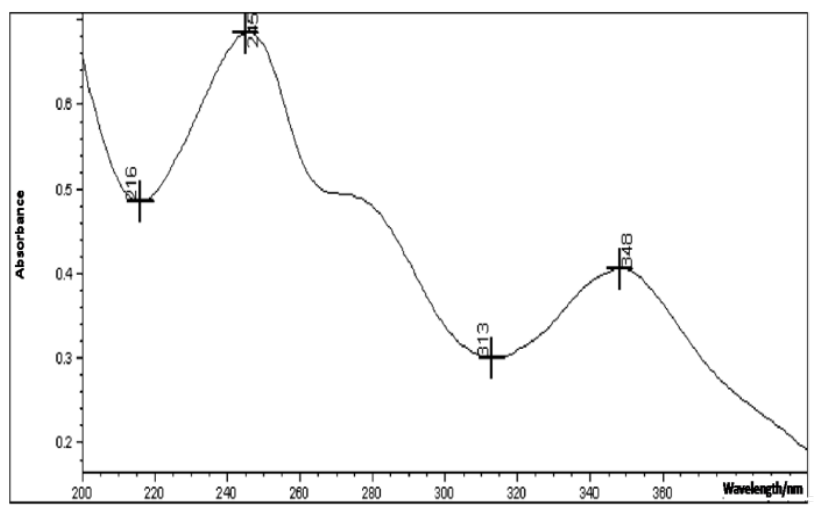

Figure 3. Ultraviolet absorption spectra of tigecycline in aqueous solution

For more accurate analysis, Ringbom curve was constructed and the linear range was observed. Calibration curves were constructed in the range of expected concentrations $\left(10-22 \mu \mathrm{g} \mathrm{mL}^{-1}\right)$. Beer's law is obeyed over this concentration range. The value of the determination coefficient calculated $\left(\mathrm{r}^{2}=0.9998, \mathrm{y}=0.0354 \mathrm{x}+0.0003\right.$, where, $\mathrm{x}$ is concentration and $\mathrm{y}$ is the absorbance value) indicated the linearity of the analytical curve for the method (Table 1).

Table 1. Analytical Parameters for the Determination of Tigecycline Using the Proposed Methods

\begin{tabular}{|c|c|c|}
\hline & $\begin{array}{c}\text { UV- spectropho- } \\
\text { tometry }\end{array}$ & $\begin{array}{c}\text { Visible- spectro- } \\
\text { photometry }\end{array}$ \\
\hline $\begin{array}{c}\text { Analytical wave- } \\
\text { length/nm }\end{array}$ & 245 & 378 \\
\hline${\text { Linearity range/ }\left(\mu \mathrm{g} \mathrm{ml}^{-1}\right)}^{-2}$ & $10-34$ \\
\hline $\begin{array}{c}\text { Regression equation } \\
(\mathrm{A}=\mathrm{aC}+\mathrm{b})\end{array}$ & $10-22$ & \\
\hline Slope $(\mathrm{a})$ & 0.0354 & 0.0249 \\
\hline Intercept $(\mathrm{b})$ & 0.0003 & 0.0043 \\
\hline LOQ & 0.33 & 0.29 \\
\hline LOQ & 1.00 & 0.89 \\
\hline Determination coefficient & 0.9998 & 0.9997 \\
\hline
\end{tabular}

The LOD and LOQ were found to be 0.33 and $1.00 \mu \mathrm{g}$ $\mathrm{mL}^{-1}$, respectively. According to ANOVA there are linear regression and no deviation from linearity. The experimental values obtained for the determination of tigecycline in samples, indicated a satisfactory intra-day variability (R.S.D. of $1.12 \%$ ) and intermediate precision (R.S.D. $<1.03 \%$ ) (Table 2).

Table 2. Inter-day and between-analysts precision data of UV and visible methods for tigecycline in pharmaceutical product

\begin{tabular}{|c|c|c|c|}
\hline Method & Sample & $\begin{array}{l}\text { Inter-Day } \\
\text { RSD }^{\mathrm{a} /}(\%) \\
\end{array}$ & $\begin{array}{c}\text { Between- } \\
\text { Analysts RSD } /(\%) \\
\end{array}$ \\
\hline \multirow{2}{*}{$\begin{array}{c}\text { UV- } \\
\text { spectrophotometry }\end{array}$} & 1 & 1.01 & 1.03 \\
\hline & 2 & 0.22 & 0.52 \\
\hline \multirow{2}{*}{$\begin{array}{l}\text { Visible- } \\
\text { spectrophotometry }\end{array}$} & 1 & 0.73 & 1.83 \\
\hline & 2 & 0.36 & 0.11 \\
\hline
\end{tabular}

${ }^{a}$ Relative standard deviation

A good accuracy of the method was verified with a mean recovery of $100.84 \%$ (Table 3). Variations in the wavelength to method robustness evaluation showed R.S.D. $<0.27 \%$ (Table 4).

Table 3. Accuracy of UV and Visible Spectrophotometric Methods for Tigecycline in Pharmaceutical Products

\begin{tabular}{|c|c|c|c|}
\hline Method & $\begin{array}{c}\text { Sample } \\
\text { concentration }\end{array}$ & $\begin{array}{c}\text { Added concen- } \\
\text { tration } /\left(\mu \mathrm{g} \mathrm{ml}^{-1}\right)\end{array}$ & $\begin{array}{c}\% \text { Recovery }^{\mathrm{a}} \pm \\
\mathrm{RSD}^{\mathrm{b}} /(\%)\end{array}$ \\
\hline \multirow{2}{*}{$\begin{array}{c}\text { UV-spectrop } \\
\text { hotometry }\end{array}$} & 10 & 2.8 & $100.32 \pm 0.82$ \\
\cline { 2 - 4 } & 10 & 6.0 & $100.78 \pm 0.52$ \\
\hline \multirow{2}{*}{$\begin{array}{c}\text { Visible- } \\
\text { spectropho- } \\
\text { tometry }\end{array}$} & 10 & 9.2 & $101.42 \pm 1.55$ \\
\cline { 2 - 4 } & 14 & 3.6 & $99.69 \pm 0.94$ \\
\cline { 2 - 4 } & 14 & 8.0 & $99.34 \pm 0.71$ \\
\hline
\end{tabular}

${ }^{\mathrm{a}}$ Mean of three replicates; ${ }^{\mathrm{b}}$ Relative standard deviation.

\subsection{Visible Method}

In the determination of the method conditions different buffer $\mathrm{pH}$ and copper concentration were evaluated. Variable amounts of copper solution $(0.1-2 \mathrm{~mL})$ were studied with fixed $\mathrm{pH}$ and tigecycline concentration. The volume of $1 \mathrm{~mL}$ of copper solution showed major absorbance values (Figure 4).

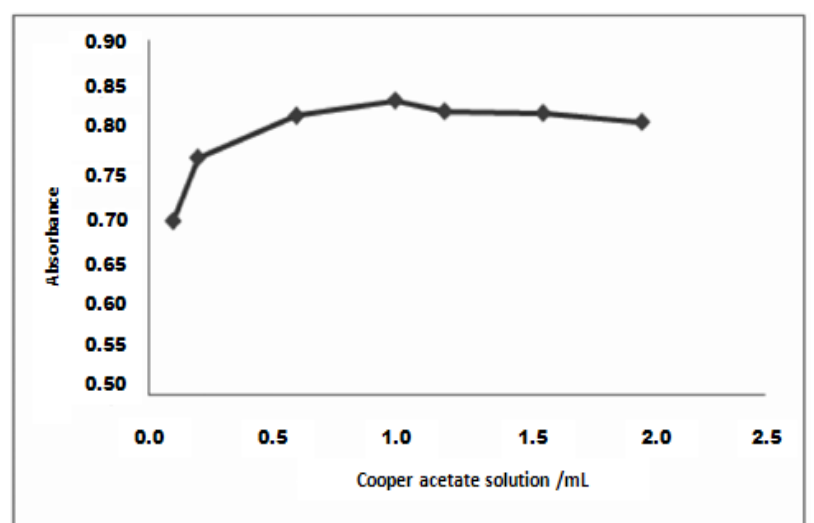

Figure 4. Effect of copper solution volume on the absorbance of $34 \mu \mathrm{g}$ $\mathrm{mL}^{-1}$ of tigecycline 
Table 4. Robustness Evaluation of UV and Visible Spectrophotometric Methods to Determination of Tigecycline in Pharmaceutical Products

\begin{tabular}{|c|c|c|c|c|}
\hline Method & Variable & $\begin{array}{l}\text { Investigated } \\
\text { range }\end{array}$ & $\begin{array}{c}\text { Tigecycline }{ }^{a} \\
(\%)\end{array}$ & $\begin{array}{l}R S D^{b /} \\
(\%)\end{array}$ \\
\hline \multirow{3}{*}{$\begin{array}{c}\text { UV- } \\
\text { spectropho- } \\
\text { tometry }\end{array}$} & \multirow{3}{*}{$\begin{array}{l}\text { Wavelength/ } \\
\mathrm{nm}\end{array}$} & 243 & 108.96 & \multirow{3}{*}{0.10} \\
\hline & & 245 & 109.16 & \\
\hline & & 247 & 109.12 & \\
\hline \multirow{9}{*}{$\begin{array}{l}\text { Visible- } \\
\text { spectropho- } \\
\text { tometry }\end{array}$} & \multirow{3}{*}{$\begin{array}{c}\text { Wavelength/ } \\
\mathrm{nm}\end{array}$} & 376 & 110.53 & \multirow{3}{*}{0.13} \\
\hline & & 378 & 110.64 & \\
\hline & & 380 & 110.82 & \\
\hline & \multirow{3}{*}{ Buffer $\mathrm{pH}$} & 2.5 & 110.24 & \multirow{3}{*}{0.28} \\
\hline & & 3.0 & 110.64 & \\
\hline & & 3.5 & 110.04 & \\
\hline & \multirow{3}{*}{$\begin{array}{c}\text { Copper } \\
\text { solution } / \mathrm{mL}\end{array}$} & 0.8 & 110.99 & \multirow{3}{*}{1.04} \\
\hline & & 1.0 & 110.64 & \\
\hline & & 1.2 & 108.85 & \\
\hline
\end{tabular}

${ }^{\mathrm{a}}$ Mean of three replicates; ${ }^{\mathrm{b}}$ Relative standard deviation.

After copper concentration determination, the following buffers and $\mathrm{pHs}$ were evaluated: sodium acetate $(\mathrm{pH} \mathrm{3.0)}$, ammonium acetate ( $\mathrm{pH}$ 5.0), potassium phosphate ( $\mathrm{pH} 7.5)$ and Tris ( $\mathrm{pH}$ 8.6). Besides, the influence of temperature and light in the absorbance was determined. The best results were obtained with $1 \mathrm{~mL}$ of copper solution and sodium acetate ( $\mathrm{pH}$ 3.0) buffer. The $\mathrm{pH}$ show low influence in the reaction, with similar absorbances at pHs 3.0, 5.0 and 8.6, however when the phosphate buffer was used, turbidity was observed, that may be related to copper precipitation occurring as oxides and hydroxides, at $\mathrm{pH}$ levels higher than 5 or $6[19]$. The acid $\mathrm{pH}$ was chosen because in this $\mathrm{pH}$ tigecycline is incolor and there is not interference in the color of the reaction product. Then, the green color observed is from reaction product and not from mixture of yellow tigecycline and blue copper acetate solutions. A decrease in absorbance was observed after $15 \mathrm{~min}$ at $40^{\circ} \mathrm{C}$. The reaction was stable for 30 minutes, in the presence or not of light. At $\mathrm{pH} 3.0$, a maximum absorbance wavelength of $350 \mathrm{~nm}$ to tigecycline in aqueous solution was observed and, after addition of copper solution, this maximum increased to $378 \mathrm{~nm}$, indicating the occurrence of the reaction (Figure 5).

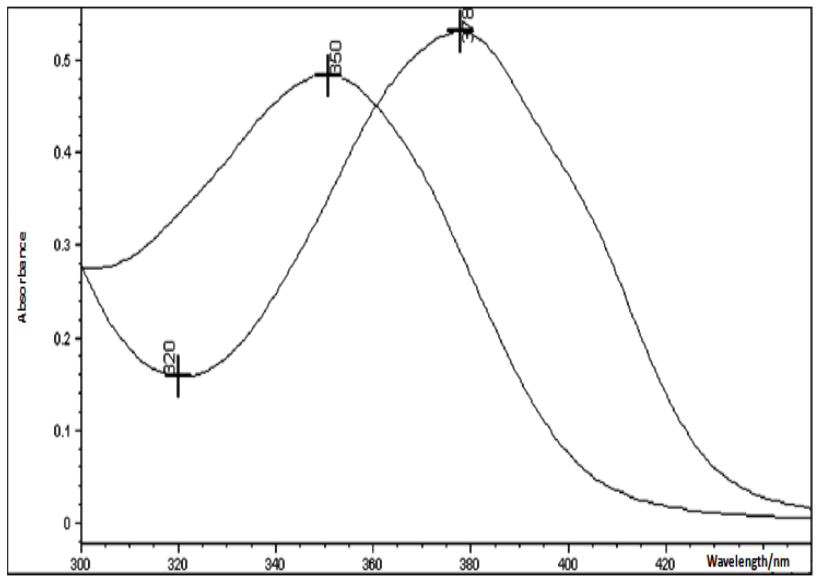

Figure 5. Absorption spectrum of tigecycline in the presence $(\lambda \max =378$ $\mathrm{nm})$ and absence $(\lambda \max =350 \mathrm{~nm})$ of copper solution at $\mathrm{pH} 3.0$

The reaction mechanism between tigecycline and copper was not elucidated, since this work is the first study that applies this reaction. Although, for tetracylines analogs it is shown that the first donor group to bind copper is the $\mathrm{O} 3$ atom, which starts deprotonating at relatively low $\mathrm{pH}$. When the $\mathrm{pH}$ is raised chelation taking place at the O10-O12 system as the $\mathrm{OH} 12$ group dissociates. The ultimate ligand deprotonation at the $\mathrm{C} 4$ dimethylammonium group leads to the chelate formation, with a new change in the binding mode in favor of the N4-OH12, donor set[20].

The analytical curves constructed for tigecycline were found to be linear in the $10-34 \mu \mathrm{g} \mathrm{mL}^{-1}$ range. The value of the determination coefficient calculated $\left(r^{2}=0.9997, y=\right.$ $0.0249 \mathrm{x}-0.0043$, where, $\mathrm{x}$ is concentration and $\mathrm{y}$ is the absorbance) indicated the linearity of the analytical curve for the method. The precision, evaluated as the repeatability of the method, was studied by calculating the relative standard deviation (RSD) for six determinations of the $22 \mu \mathrm{g} \mathrm{mL} \mathrm{L}^{-1}$, performed on the same day and under the same experimental conditions. The obtained RSD value was $0.34 \%$. The intermediate precision was assessed by analyzing two samples of the pharmaceutical formulation on three different days (inter-day); the mean values obtained were 110.79 and $119.47 \%$ with RSD 0.73 and $0.36 \%$, respectively. The between analysts precision was determined by calculating the mean values and the RSD for the analysis of two samples of the pharmaceutical formulation by two analysts; the mean values were found to be 110.23 and $119.53 \%$ with RSD 1.83 and $0.11 \%$, respectively. The results are shown in Table 2 . The accuracy was assessed from three replicate determinations of three different solutions containing 17.6, 22 and $26.4 \mu \mathrm{g}$ $\mathrm{mL}^{-1}$. The absolute means obtained for tigecycline are shown in Table 3 with a mean value of $99.10 \%$, demonstrating that the method is accurate within the desired range. For calculating of the LOD and LOQ, a calibration equation, $y=30773.77 x+62280.15$, was generated by using the mean values of the three independent analytical curves. The LOD and LOQ calculated were 0.29 and $0.89 \mu \mathrm{g} \mathrm{mL}^{-1}$, respectively. The results and the experimental range of the selected variables evaluated in the robustness assessment are given in Table 4.

Table 5. Determination of tigecycline in pharmaceutical products by the $\mathrm{UV}$ and visible methods

\begin{tabular}{|c|c|c|c|c|c|}
\hline & \multicolumn{2}{|c|}{ Label claim } & \multicolumn{3}{c|}{ Experimental amount } \\
\hline & & Tigecycline & \multicolumn{3}{|c|}{ Tigecycline $^{\mathrm{a}}$} \\
\hline Method & $\begin{array}{c}\text { Sam- } \\
\text { ple }\end{array}$ & $\begin{array}{c}\mathrm{mg} \\
\text { per vial }\end{array}$ & $\mathrm{mg}$ & $\begin{array}{c}\text { Recov- } \\
\text { ery/ (\%) }\end{array}$ & $\begin{array}{c}\mathrm{RSD}^{\mathrm{b}} / \\
(\%)\end{array}$ \\
\hline $\begin{array}{c}\text { UV- } \\
\text { spectrophotometry }\end{array}$ & 1 & 50 & 55.57 & 111.14 & 0.83 \\
\cline { 2 - 6 } $\begin{array}{c}\text { Visible- } \\
\text { spectrophotometry }\end{array}$ & 2 & 50 & 61.21 & 122.41 & 0.41 \\
\cline { 2 - 6 } & 2 & 50 & 55.19 & 110.37 & 0.54 \\
\hline
\end{tabular}

${ }^{\mathrm{a}}$ Mean of three replicates; ${ }^{\mathrm{b}}$ Relative standard deviation.

\subsection{Methods Application}

The proposed spectrophotometric methods were applied for the determination of tigecycline in lyophilized powder, without prior separation of the excipient of the formulation, 
showing the applicability of the method for quality control analysis (Table 5). The results demonstrated elevated tigecycline content in the samples, however these results are not considerate irregulars since official reference standard and specifications for tigecycline in lyophilized powder are not established yet.

\section{Conclusions}

In this work, analytical ultraviolet and visible spectrophotometric methods were developed for quantitative determination of tigecycline in lyophilized powder. Its advantages over other existing methods are its simplicity, fastness and low-cost conditions. Moreover, it does not use polluting reagents. All validation parameters were found to be highly satisfactory, indicating linearity, selectivity, precision, accuracy, robustness and adequate detection and quantification limits. The method, therefore, can be easily applied in routine quality control laboratories.

\section{ACKNOWLEDGEMENTS}

The authors wish to thank FAPESP (Fundação de Amparo à Pesquisa do Estado de São Paulo, project 2009/53434-2), CNPq (Brasília, Brazil), and PADC-FCF, FUNDUNESP (São Paulo, Brazil) for the financial support.

\section{REFERENCES}

[1] Bauer, G., Berens, C., Projan, S. J., Hillen, W., 2004, Comparison of tetracycline and tigecycline binding to ribosomes mapped by dimethylsulphate and drug-direct $\mathrm{Fe}^{2+}$ cleavage of 16S rRNA, J. Antimicrob. Chemother., 53, 592-599

[2] Chopra, I., 2001, Glycylcyclines: third-generation tetracycline antibiotics, Curr. Opin. Pharmacol., 1(5), 464-469

[3] Zhanel, G. G., Homenuik, K., Nichol, K., Noreddin, A., Vercaigne, L., Embil, J., Gin, A., Karlowsky, J. A., Hoban, D. J., 2004, The glycylcyclines: a comparative review with the tetracyclines, Drugs, 64(1), 63-88

[4] Pankey, G. A., 2005, Tigecycline, J. Antimicrob. Chemother., 56(3), 470-480

[5] Garrison, M. W., Neumiller, J. J., Setter, S. M., 2005, Tigecycline: an investigacional glycylcycline antimicrobial with activity against resistant Gram-positive organisms, Clin. Ther., 27(1), 12-22

[6] Hoffmann, M., Demaio, W., Jordan, R. A., Talaat, R., Harper, D., Speth, J., Scatina, J., 2007, Metabolism, excretion, and pharmacokinetics of $\left[{ }^{14} \mathrm{C}\right]$ tigecycline, a first-in-class glycylcycline antibiotic, after intravenous infusion to healthy male subjects, Drug. Metab. Dispos., 35(9), 1543-1553

[7] Doan, T., Fung, H. B., Mehta, D., Riska, P. F., 2006, Tigecycline: A glycylcycline antimicrobial agent, Clin. Ther., 28(8), 1079-1106

[8] Li, C., Sutherland, C. A., Nightingale, C. H., Nicolau, D. P.,
2004, Quantitation of tigecycline, a novel glycylcycline, by liquid chromatography, J. Chromatogr. B, 811(2), 225-229

[9] Bradford, P. A., Petersen, P. J., Young, M., Jones, C. H., Tischler, M., O'Connell, J., 2005, Tigecycline MIC testing by broth dilution requires use of fresh medium or addition of the biocatalytic oxygen-reducing reagent oxyrase to standardize the test method, Antimicrob. Agents Chemother., 49(9), 3903-3909

[10] Muralidharan, G., Micalizzi, M., Speth, J., Raible, D., Troy, S., 2005, Pharmacokinetics of tigecycline after single and multiple doses in healthy subjects, Antimicrob. Agents Chemother., 49(1), 220-229

[11] Silva, L. M., and Salgado, H. R. N., 2010, Tigecycline: A Review of properties, applications, and analytical methods, Ther. Drug Monitor., 32(3), 282-288

[12] Conte Jr, J. E., Golden, J. A., Kelly, M. G., Zurlinden, E., 2005, Steady-state serum and intrapulmonary pharmacokinetics and pharmacodynamics of tigecycline, Int. J. Antimicrob. Agents, 25(6), 523-529

[13] Ji, A. J., Saunders, J. P., Wadgaonkar, N. D., Petersen, P. J., O’Leary, K., McWilliams, W. E., Amorusi, P., Leal, M., Fluhler, E. N., 2007, A novel antibiotic bone assay by liquid chromatography/tandem mass spectrometry for quantitation of tigecycline in rat bone, J. Pharm. Biomed. Anal., 44(4), 970-979

[14] Ji, A. J., Saunders, J. P., Amorusi, P., Wadgaonkar, N. D., O’Leary, K., Leal, M., Dukart, G., Marshall, B., Fluhler, E. N., 2008, A sensitive human bone assay for quantitation of tigecycline using LC/MS/MS, J. Pharm. Biomed. Anal., 48, 866-875

[15] Marona, H. R. N., and Schapoval, E. E. S., 2001, Spectrophotometric determination of sparfloxacin in pharmaceutical formulations using bromothymol blue, J. Pharm. Biomed. Anal., 26(3), 501-504

[16] Kumar, R. S., Manjunatha, D. H., Shaikh, S. M. T., Seetharamappa, J., Harikrishna, K., 2006, Sensitive extractive spectrophotometric methods for the determination of trazodone hydrochloride in pharmaceutical formulations, Chem. Pharm. Bull., 54(7), 968-971

[17] Amin, A. S., Ahmed, I. S., Dessouki, H. A., Mohamed, H. A., 2010, Spectrophotometric quantification of fluoxetin hydrochloride: application to quality control and quality assurance processes, Chem. Pap., 64(3), 278-284

[18] ICH Q2(R1). Validation of Analytical Procedures: Text and Methodology, International Conference on Harmonization of Technical Requirements for the Registration of Pharmaceutical for Human Use, Geneva, Switzerland, 2005

[19] Couto, C. M. C. M., Lima, J. L. F. C., Conceição, M., Montenegro, B. S. M., Reis, S., 1998, Tetracycline, oxytetracycline and chlortetracycline determination by flow injection potentiometry, J. Pharm. Biomed. Anal., 18, 527-533

[20] Jezowska-Bojczuk, M., Lambs, L., Kozlowski, H., Berthon, G., 1993, Metal ion-tetracycline interactions in biological fluids. 10. Structural investigations on copper (II) complexes of tetracycline, oxytetracycline, chlortetracycline, 4- (dedimethylamino) tetracycline, and 6-desoxy -6- demethyltetracycline and discussion of their binding modes, Inorg. Chem., 32(4), 428-437 